\title{
SOME RECENT ADVANCES IN CHEMOTHERAPEUTIC DRUGS
}

\author{
By JOHN ALMEYDA, M.R.C.S., D.P.H.(Lond.) \\ (Chief Clinical Assistant, Royal Chest Hospital)
}

It is proposed to discuss two groups of drugs, biochemotherapeutic and chemotherapeutic drugs. The intense growth of both these groups has occurred almost simultaneously.

\section{Biochemotherapeutic Drugs}

These are anti-bacterial agents and their source is the living cell. Dubos and Avery (I93I), at the Rockefeller Institute, were the first to show that their mechanism of protection was not the destruction of the bacterial cell but the removal of the cell's capsular armour, which would be later infested by the phagocytes. The next step in research was devoted to the microorganisms, which would attack the living cell of unrelated species, and isolate the responsible chemical principles, which could be utilised as bacteriacidal or bacteriostatic agents. These chemical-constitutions have now been isolated from fungi and bacteria. They are Tyrothricin, Tyrocidin, Gramicidin, Penicillin, Actinomycin, Citrinin, Streptothricin, Gliotoxin, and Proactinomycin. Only the first four will be discussed here as they are the least toxic.

\section{A. Tyrothricin.}

This was isolated by Hotchkiss and Dubos (I940). It is an alcohol and water soluble fraction, obtained from certain aerobic sporulating bacilli found in the soil. In vitro it has strong bacteriacidal properties for many gram + ve and a couple of gram - ve organisms. It is impure, and from it two crystalline materials, Tyrocidin and Gramicidin, have been separated. Both these crystalloids are soluble in water, but insoluble in alcohol. They have different chemical compositions and biological characteristics.

\section{Tyrocidin.}

This is a non-specific general protoplasmic poison. It is antibacterial for both gram +ve and gram - ve organisms. It destroys the metabolic activity of the cell and diminishes its oxygen uptake. It is, however, essentially ineffective in vivo. It is toxic in animals.

\section{Gramicidin.}

This crystalloid does not act like a general protoplasmic poison. It does not interfere with the oxygen uptake of the bacterial cell. It is essentially a bacteriostatic agent. It loses very little of its activity in the presence of animal tissues, like peptones or sera. It is highly specific for gram + ve organisms, e.g. pneumococci, streptococci, etc., and gram - ve organisms such as meningococci and gonococci. It has no effect on gram -ve bacilli. It does not act by intravenous, muscular, or subcutaneous injections, because it is highly insoluble in blood. It is toxic to animals. Its uses, therefore, are limited to its local action, such as for ulcers of the skin, skin infections, mastoids, empyemata and osteomyelitis.

\section{B. Penicillin.}

This was first produced by Fleming (I929), from the Penicillin Notatum. In the last two years Chain, Florrey, and their colleagues at Oxford have demonstrated that Penicillin possesses remarkable anti-bacterial activity against certain organisms, and because of its low toxicity it holds great therapeutic possibilities. It can inhibit the growth of gram + ve bacilli in dilutions of $I / I, 000,000$ and yet it could be injected intravenously into mice without producing ill-effects. A further purification of Penicillin has been reported by Abraham and Chain, and studied by Florrey and Jenning. They find that this new Penicillin can inhibit the growth of staphylococci in $\mathrm{I} / 25,000,000$ dilution.

Penicillin is a complex molecule and its instability towards acids, alkalies, heavy metals, and many other chemical re-agents, makes the task of elucidating its structure more than usually difficult, so that the prospects of synthesis still seem remote. It is freely soluble in water and is destroyed in acid solution. It is therefore not suitable for oral administration, but is highly effective intravenously. The dosage recommended being 15,000 units every four hours. -Its 
toxicity is low and is fairly rapidly excreted, chiefly by the kidneys. Penicillin does not act in the manner of an anti-septic agent, since it does not "interfere with the oxygen uptake of the organisms. In a specific way it interferes with the growth of bacteria, but does not destroy them. The drug is bacteriostatic and does not affect W.B.C.'s. It is therefore useful for local application.

It is a biochemotherapeutic agent, even more remarkable than the studies of the partially purified product foreshadowed. It is active against many gram + ve organisms, and is infinitely less toxic than the least toxic of the sulphonamides. Its antibacterial activity is not affected in tissue constituents, or within wide limits by the bacteria present. Penicillin is even active against the sulphonamide resistant streptococci.

\section{Chemotherapeutic Drugs}

So much has been written on the sulphonamide group that only the most recent additions to the already formidable list will be dealt with here.

\section{A. Sulphamezathine. (Macartney, I942).}

It is a dimethyl sulphadiazine, and is a pale crystalline material. Its bacteriostatic effects, speed of absorption and elimination, are the same as sulphadiazine. It is highly soluble. The concentration of the drug in the C.S.F. is fairly high. Its toxic effects are few. There are no crystals in the urine, and the non-protein-nitrogen level in the blood remains unaltered. It has a higher efficiency than sulphadiazine, because it is highly soluble and relatively free from toxicity, namely, renal irritation and obstruction.

\section{B. Sulphaguanidine.}

Attempts at sterilisation of the intestine by drugs have brought forward a new sulphonamide in Sulphaguanidine (Roblin, I942). This drug is soluble in water. Its absorption from the intestinal tract is fairly slow, and its excretion is rapid. Because of these characteristics it is used in the treatment of intestinal infections, such as dysentery, cholera, typhoid, and the sterilisation of the intestinal tract prior to operative interference. It has, however, been proved to be far from a safe drug, as toxic effects are always present. It has been suggested that, asco bowel organisms which play a part in the synthesis of essential nutrients are destroyed by sulpha- ? guanidine, it gives rise to nutritional deficiency. Because of these drawbacks a new drug Succinyl Sulphathiazol (Sulphasuxidine) which is less absorptive, has been introduced. Its future appears to be promising (Moore \& Miller, I942).

As the various sulphonamides have the same "mode of action," dosage, "mode of administration," "intolerance and toxicity," and "drugfastness," these features can be described as for the whole group.

\section{Mode of Action.}

The various surphonamides exert their bacteriostatic action by interfering with the function of the p-amine benzoic acid in the bacterial cell (D. D. Wood, I940). The compounds are members of the B complex and are apparently essential parts of the enzymic system of certain bacteria. When the drug action is complete, the bacteria cease to grow.

\section{Dosage and mode of administration.}

The effective dosage and mode of administration of all the sulphonamides are essentially identical. The goal to be set is a maximum concentration in the blood in a few days. A dosage level showing effective results within a few days is not likely to be successful, if continued with, unless there is also impaired excretion. The guide to variations from the average plan of dosage is the condition of the patient, the presence or absence of therapeutic or toxic effects.

A good working rule for dosage is I grm. per $20 \mathrm{lb}$. of body weight in adults, and $\mathrm{I} \frac{1}{2} \mathrm{grm}$. per $20 \mathrm{lb}$. of body weight in children, for the first two days. Then reduce the dosage by $50 \%$ for the next ten days. The drug should not be continued with after this. The modes of administration are orally, rectally, intravenously and by inunction.

On an average, $6 \mathrm{grm}$. daily doses give blood levels of ro mgm. But differences in these levels may be due to differences in speed, completeness of absorption, and also the speed of elimination. 
The bacteriostatic power of the sulphonamides depends upon such factors as the quality of the medium in which the organisms grow, the temperature, the $\mathrm{Ph}$ of the medium, the concentration of organisms, the resistance of the strain, and the speed with which it acetylates the drug, since the more it is conjugated the less is its bacteriostatic action. Some, or all, of these factors may differ from patient to patient.

The blood concentration of the drug should always be estimated, if $20 \mathrm{grm}$. have been consumed in 2 or 3 days, as this is usually its toxicity level. Sulphathiazol and sulphanilamides are rapidly absorbed and their concentration is reached in one hour or less. Elimination is also quite rapid. Sulphadiazine and sulphapyridine absorption goes on over a period of 4 to 6 hours, proceeding along slowly. Cumulation to toxic levels is more likely.

\section{Intolerance and toxicity.}

The oral administration or local application of a sulphonamide compound may be attended by various manifestations of intolerance and toxicity. These may be due to a direct toxic action of the drug by its mechanical obstruction, or to some form of sensitisation. These sensitisation phenomena are of several types. The reactions may occur early in treatment, possibly, as a result of toxin liberation, or to an acquired "allergy." It seems that the antigen responsible for the "allergy" is not the drug itself but a combination of it with body proteins, i.e. the protein behaves as a foreign protein after combination with the drug (Wedren's experiment). Nearly a third of Sulphathiazol cases become allergic. The incidence of sulphonamide sensitisation and toxicity may be minimised if :-

(I) Medication is restricted to 7 days, or less. Whenever possible, and only when indicated, small doses should be used initially for certain chronic infections associated with a chronic focus.

(2) Desensitisation be undertaken immediately if "allergy" is encountered on or after the eighth day.

(3) Exposure to sunlight be restricted during such treatment.

(4) The drug be withheld if Werner's test indicates retention. (I c.c. urine diluted ro times to a few drops of Werner's solution, i.e. $3 \%$ paradimethylamine-benzaldehyde in $7 \%$ sulphuric acid, gives a flavine-yellow colour.)

Concerning its tonic effects one can only say that the sulphonamides are potentially dangerous drugs, and that no bodily system is immune. They are:-

\section{Renal (hematuria, renal calculi, and anuria).}

They are due chiefly to precipitation of the insoluble compounds, namely, the acetylated form of the drug in the tubules and renal pelvis. The crystals irritate the kidney, giving rise to renal bleeding and obstruction to the production and flow of urine. The common findings are concretions in both kidneys and ureters. Rarely, in fatal cases, there is great tubular and capsular dilatation, with marked congestion and vacuolisation within the glomerular tufts, and an acute haemorrhagic pyclo-ureteritis extending into the adjacent renal medullary tissue.

\section{Agranulocytosis.}

This is a grave complication but seldom fatal. The time of its occurrence varies, but it usually appears some days after the drug has been withdrawn. Although some cases are due to idiosyncrasies, most cases are due to overdosage (e.g. $54 \mathrm{grm}$. in I4 days). If 20 grm. have been given in the space of $2 / 3$ days, one should arrange a blood test. If the white cells have dropped to 4,000 the drug should be stopped, and if the white cells continue to drop then blood transfusions, pentonucleotides, yellow marrow extracts or sodiumnucleinate should be given. It must be remembered that a low white count prior to this form of therapy does not contra-indicate its use.

\section{Minor toxic symptoms.}

Nausea, vomiting, asthenia, dizziness, slight acidosis, and depression, are some of the minor toxic symptoms. They occur in the early stages (I-2 days) and then pass off. Cessation of the treatment is rarely required, unless vomiting is severe. Parental and rectal 
administration may be tried, and in nervous subjects may prove successful, although the majority of these symptoms are due to its central action. Oxygen inhalation has been used with success in combating these symptoms.

Another drawback is cyanosis. Varying degrees of cyanosis often appear early in treatment and are due to the presence of meth- and sulph-haemoglobinaemia. This can be prevented if sulphur feeds are not consumed during treatment. When present this can be treated, with methylene-blue $0.5 \mathrm{grm}$. bd. or 50 with tab. nicotinic acid mgms. T.I.D.

\section{Nervous manifestations.}

Repeated administration of the sulphonamides seems to sensitise the nervous system. The toxic manifestations are headaches, dizziness, depression, confusion, aphasia, stammering, toxic psychoses, meningeal symptoms, blindness, convulsions, myelitis, encephalomyelitis, optic-neuritis, peripheral neuritis, and minor disturbances of judgment and memory. Preventive measures should include careful dosage and early detection of these features. When present the drug should be discontinued. In the case of air-pilots, they should stay indoors and rest. The patient should be warned against driving, or reaching important decisions, or even signing documents or wills.

\section{Skin rashes.}

These are of various types-morbiliform, nodular, erythymatous, urticarial, scarlatini-form, or purpuric. Sulphathiazol often gives a characteristic rash which is nodular. There appears to be no co-relation between the level of the drug in the blood and the development of the rash, although the discontinuance of the drug, and the giving of adequate fluids, do hasten the elimination of the toxic products. In the majority of cases these rashes are due to "allergy." It seems that the antigen responsible for the allergy is not the drug itself but a combination of it with the body-proteins, i.e. the protein behaves as a foreign protein after combination with the drug. Preventive measures consist of desensitisation by continuing with the same drug, and refraining from direct sunlight. If, however, Werner's test is positive, indicating drug retention, then the drug should be discontinued. Nicotinic acid has been found to be of much help as it acts specifically.

\section{Jaundice}

Jaundice is the result of toxic effects of the drug, due either to an haemolytic anaemia, or toxic hepatitis. Preventive measures are the frequent examinations of the blood to exclude anaemia, and the taking of a Van den Berg test. If present, then one should suspend the treatment, increase the fluid intake, give glucose, injections of calcium gluconate, and blood-transfusions.

\section{Inhibition of spermatogenesis and}

8. Interstitial Myocarditis are other remote toxic effects of the sulphonamides. So few cases have been recorded that the adoption of preventive measures or treatment cannot be dictated with much certainty.

\section{Choice of Sulphonamides.}

The choice of a particular sulphonamide will be dependent on the type of organism invading, and the stage of infection at which the drug is employed. Of these new drugs sulphadiazine is undoubtedly the most efficacious of the group; it is particularly useful in gonococcal infections. Sulphathiazol is indicated for staphylococcal infections, and sulphaguanidine for all forms of intestinal infections, but, in view of its toxity succinyl sulphathiazol is now being tried out and promises to be the drug of choice.

\section{Drug-fastness.}

Resistance to the sulphonamides seems a characteristic of certain strains of organisms. Others are even able to acquire this high resistance if exposed to sublethal doses of this group, e.g. pneumococci, gonococci, staphylococci and B. coli. This drug fastness may develop very rapidly within 3 days of treatment. The mechanism involved is not known. It may be similar 
to other kinds of acquired resistance. Preventive measures should be vigorous, with large doses, if one is to prevent drug-fastness developing. The widespread use of small doses of sulphonamides should.be deprecated for fear of cultivating a drug-fastness. Viewed in its right perspective this then becomes a public health problem, as these drugs are now being used so freely in so many diseases.

\section{REFERENCES}

ABRAHAM, E. P., CHAIN, E., FLOREY, H. W., et al. (1941), Lancet, 2, 177

DUBOS, R. J., and AVERY, O. T. (I93I), Exper. med., 54, 5I.

FLEMING, A. (1929), Brit. J. Exper. Path., 10, 226.

GOLD H. (1943), Bull. N.Y. Aced. of Med.' Feb., I32.

HOTCHKISS, R. D., and DUBOS, R. J. (1940), J. Biol. Chem., 136, 883.

MACARTNEY, D. W. (1942), Lancet, 1, 639.

MOORE, M. L., and MILLER, C. S. (1942), J. Am. Med. Assoc., 62, 1572.

ROBLIN, R. O.' (I940), J. Amer. Chem. Soc., 62 , r999.

WOOD, D. D. (1940), Brit. J. Exper. Path., 21, 74.

\section{CORRESPONDENCE}

DEAR SIR,

\section{THE WHITE PAPER}

I see that in the April number of the Post-Graduate Medical Journal you invite views on the proposed National Health Service.

I am young (aged 25), qualified from Middlesex Hospital two years ago, and am passionately fond of medicine.

The following are my views and constructive suggestions:

I. Should the Health Service be FREE?

It is ludicrous to expect a completely free medical service. The public will pay for it out of their income tax, etc., so why not come out into the open, face facts, and institute a system akin to the paying of premiums to a National Insurance Company?

2. Municipal and County v. Voluntary Hospitals.

I was studying, as a student, at one of the Middlesex County Hospitals. I am sure that the patients got the best possible treatment there. I propose more modern, richer and greatly increased numbers of hospitals such as this one. America has them-why not England? If there are going to be Voluntary Hospitals let the voluntary contributions be divided between them. I propose more hospitals whose wards are run by general practitioners, who can thus see their cases from start to finish. This works well in Canada - why not in England? People should be urged to donate more to medicine and less to dogs' homes, etc.

3. Is it sinful for a doctor to earn money?

Certain members of the public seem to be labouring under the delusion that doctors are mentally deranged angelic philanthropists who love nothing more than to work all day and all night-for no money at all!! I feel that it should be explained, through the Press, if necessary, that doctors are human beings who likf eating. (Anyway, whether a thing is "sinful" or not is completely dependent on an individual's religion and/or ideals.)

4. Does the competitive spirit among doctors make for better or worse medicine?

(a) When doctors steal patients from each other (I don't know much about this variety of practitioner because I shun them like the plague), I am sure that it must produce bad medicine.

(b) When doctors vie with each other to produce advances in medicine and to solve problems before each other this produces good medicine.

5. Psychiatric Services.

(a) Many more social psychiatric workers and clinics necessary.

(b) Much mental disease is due to lack of money and education, therefore largely an economic and educational problem.

6. Relation between Service Medicine and any future National Health Service.

(a) The R.A.M.C. is an efficient soulless machine, necessary in this grim conflict. In peacetime the National Health Service has no need to be soulless, and doctors should be allowed complete freedom.

(b) I have met many M.O.'s who say that they hate the idea of any sort of medical service which resembles the R.A.M.C. with its strict discipline, etc. My views are the same.

(c) The idea that "the powers that be" should have the right to "direct" young doctors into jobs (which they may dislike) seems to me to savour strongly of the very menace that we are fighting-totalitarianism. (I feel that it would do the men who suggested this point a great deal of good if they met some Germans face to face; I am sure that they would then change their views and would favour democracy!)

I hope that these few comments may be of some interest to you, coming-as they do-from one of the younger generation, an idealist who is tremendously interested in medicine, and who has no intention whatsoever of letting any civil servant destroy its fundamental greatness.

Yours truly,

(Signed) J. G. AleXander,

Capt.R.A.M.C., C.M.F.

July 9, 1944. 